Research Article

\title{
Application of Research and Development of Intelligent Wall Insulation Materials Based on Recycling of Waste Textiles in Civil Engineering Health Monitoring
}

\author{
Zhen Li iD \\ College of Textile and Fashion, Anhui Vocational and Technical College, Hefei 230011, Anhui, China \\ Correspondence should be addressed to Zhen Li; liz@uta.edu.cn
}

Received 26 February 2021; Revised 18 March 2021; Accepted 7 April 2021; Published 19 May 2021

Academic Editor: Sang-Bing Tsai

Copyright (c) 2021 Zhen Li. This is an open access article distributed under the Creative Commons Attribution License, which permits unrestricted use, distribution, and reproduction in any medium, provided the original work is properly cited.

\begin{abstract}
In recent years, with the continuous acceleration of the country's economic construction, the demand for civil engineering construction is also deepening, and the accidents in construction are also rising. In order to reduce the occurrence of accidents, smart wall insulation materials were born. In order to achieve the best results of smart wall insulation materials, we have investigated many smart wall materials, such as waste and old, through literature research and data investigation, control products, coagulation, steel, etc. and by establishing relevant experimental models, investigating experiments to obtain experimental data, and researching the role of different materials in health monitoring. The results of the study found that, among the several materials tested, the smart wall insulation material made of the experimental waste prevention products performed the best in the health inspection, which was about $12 \%$ higher than other materials, and the waste textiles were resistant to damage. The ability is the strongest, about $10 \%$ higher than other materials, which shows that the research and development of intelligent wall insulation materials based on waste textiles can play a key role in civil engineering health monitoring.
\end{abstract}

\section{Introduction}

Circular economy is the general trend of global development. Its essence is to realize the recycling of materials while developing the economy, so as to fundamentally eliminate the sharp contradiction between environmental pollution and economic development for a long time [1]. Vigorously developing circular economy is also an important part of our country's sustainable development strategy, and it is of great significance for building a "resource-saving and environment-friendly society". The recycling and reuse of waste cotton textiles can not only save a lot of resources and increase its added value, but also reduce the environmental pollution of the textile industry, which is in line with the country's sustainable development strategy. As an emerging industry research, health monitoring technology has a wide range of applications in the field of engineering and occupies an important position in the field of smart material structures. The smart wall insulation material based on the recycling of waste textiles is a new type of smart material with wide application prospects [2].

Structural health monitoring is a field with a huge application field and will produce greater technological innovation and science. With the increase in age, the maintenance and repair costs of our existing infrastructure have attracted increasing attention. Structural health monitoring can realize the need for regular maintenance through replacement and maintenance, thereby saving unnecessary maintenance costs. On the one hand, it prevents irregular maintenance. On the other hand, for new structures, structural health monitoring sensors and systems are incorporated from the design stage. It is possible to greatly reduce the life cycle cost [3]. The aging of large-scale structures is a major issue that is concerned by engineers and scientists, and the rapid economic development has produced much higher and more stringent standards and requirements for largescale structures [4]. Nondestructive testing technology is 
especially a major issue. A large number of technologies use nondestructive testing, such as modal analysis, wave propagation, time domain analysis, eddy current methods, and ultrasonic, magnetic field methods, etc. The applications range from aircraft to infrastructure, that is, the development of large-scale structural health systems, which are widely used in bridges. For the health monitoring of structures such as buildings, as well as piezoelectric ceramic actuators and sensors, technologies based on the electrical impedance theory of piezoelectric ceramics in the high frequency range are also developing rapidly, for some small damage, such as loose bolts, defects, and cracks which are very sensitive to changes in the corresponding impedance. For the application of health monitoring in civil engineering, experts at home and abroad have many studies [5].

Liu Wei elaborated on the necessity and importance of health monitoring in civil engineering and explained the characteristics of civil engineering, focusing on how to monitor the structural health of civil engineering, and the structural health of civil engineering. The problems that are easy to appear in the monitoring and the countermeasures are organized. In the article, the relationship between engineering and maintenance costs is proposed in addition to how to effectively save maintenance costs [6].

Li Rui used examples to demonstrate that, in the process of rapid economic development in my country, the number of civil engineering constructions is also expanding, but correspondingly, there are more and more accidents caused by civil engineering. Based on this, in order to improve the safety conditions of civil engineering, it proposed to strengthen relevant health monitoring and make relevant elaboration on the significance of health monitoring and future development trends. Although the importance of health monitoring has been mentioned, it has not made relevant experimental proofs on the impact of relevant monitoring materials on health monitoring, and there is no experimental basis [7].

Yan Han introduced the most commonly used civil engineering health monitoring platforms, analyzed the advantages and disadvantages of these platforms, and creatively connected the civil engineering health monitoring platform with intelligent computing, and used computers to analyze the data and modules. The feedback scheme is processed, and the research results prove that the use of related calculations can improve the monitoring accuracy and work efficiency of related platforms [8].

The above related research has certain research significance for the health monitoring of civil engineering, but due to the data or the lack of relevant experimental proof, there are certain doubts about the conclusion. This article has made a certain understanding of the smart wall in civil engineering health monitoring by means of literature investigation and expert interviews. Afterwards, through related experiments, an experimental model was made, which proved that the smart wall made of waste textiles can play an important role in civil engineering health monitoring.

\section{Method and Function of Smart Wall Made of Waste Textiles in Health Monitoring}

2.1. Smart Wall Insulation Materials. At present, the types of thermal insulation materials in the field of construction engineering are diversified, mainly including thermal insulation mortar, rock wool, expanded perlite, foam glass, aluminum silicate products, metal foil, XPS, glass fiber wool and rock wool, and other thermal insulation materials. The thermal conductivity of the material itself mainly determines the thermal insulation effect of the material, because the application of thermal insulation materials in the building envelope can effectively reduce the heat transfer inside and outside the building, so that, in the case of natural ventilation in summer, the inner surface of the wall envelope can maintain a lower temperature and is affected by the influence of outdoor temperature and air temperature fluctuations which is small, thereby improving the insulation performance of the wall, and in the case of low outdoor temperature in winter, the enclosure structure with thermal insulation material is significantly increased due to the significant increase of heat transfer resistance, which effectively prevents heat transfer from indoor to outdoor, the indoor temperature is maintained at a certain level, and the heat preservation performance of the enclosure structure is improved. The types of building wall insulation materials are also diversified, mainly including organic materials such as EPS, XPS, and polyurethane foam, inorganic materials such as rock wool, glass wool, and foam concrete, phase change energy storage materials, and new wall insulation materials $[9,10]$.

Polyurethane foam board is a common interior wall insulation material, and its chemical raw materials are more complicated. Isocyanate and polyether are used as raw materials, and various components such as blowing agents and catalysts are filled in pressure gas tanks. When sprayed from the tank, it is foamed on site by high-pressure spraying, and it solidifies and reacts with air or moisture in the air to form a foam. The foam board can be divided into soft foam and hard foam. The soft foam has an open cell structure and the hard foam is closed pore structure [11]. Polyurethane foam panels are widely used, mainly in engineering fields such as furniture, beds, refrigeration and freezing equipment and cold storage, insulation panels, wall insulation, pipeline insulation, and storage tank insulation. However, since the foaming agent material used in polyurethane foam often uses freon, this is significant to the environment, which will destroy the atmospheric ozone layer and increase the greenhouse effect. Secondly, because the polyurethane foam board will release a large amount of toxic $\mathrm{HCN}$ gas during the combustion process, there are hidden dangers to human safety and health, and these shortcomings have limited the large-scale application of polyurethane foam panels in industry, construction, and other fields [12].

At present, common building insulation materials have disadvantages such as poor fire resistance, poor durability, easy moisture absorption, aging, and poor mechanical properties, which limit the application of commonly used 
insulation materials in construction engineering fields such as walls, and new wall insulation materials, due to their good thermal insulation, flame-retardant, anticorrosion, and strong hydrophobic properties, can effectively overcome the performance shortcomings of commonly used thermal insulation materials, showing a broader development and application prospects in the field of construction engineering [13].

At present, most literature studies and analysis of the energy consumption of thermal insulation materials often only consider the use (heating and air conditioning energy consumption) and energy consumption in the production phase, and the price of thermal insulation materials is used as the embodiment of the energy consumption in the production and part of the transportation phase. Often the calculation is not accurate. Because the energy consumption of the entire life cycle of insulation materials is closely related to the energy consumption in the phases of material acquisition, production, transportation, putting into use, and disposal, a more comprehensive determination and analysis of the model for the analysis of the investment cost and energy consumption of insulation materials is to be studied. Part of the energy consumption further studies the economy and applicability of insulation materials throughout the life cycle, making the results more accurate.

\subsection{Smart Wall Insulation Materials for Recycling of Waste} Textiles. Waste textile soft waste is produced during the processing of cotton fiber. This waste maintains the form of cotton fiber, so its recycling and reuse methods are relatively simple, fast, and inexpensive [14]. The general processing process is as follows: first classify the collected soft waste, and then wash and dry them separately to obtain products similar to nascent cotton fibers; then, these products are used as textile raw materials for spinning to form yarns which can be directly applied to the manufacture of textiles. On the other hand, the nascent cotton fiber produced from soft waste can also be used to blend with other fibers to obtain blended fabrics [15].

For pure cotton textiles, the more traditional recycling method is the physical mechanical recycling method; that is, first use a cutting machine to cut waste cotton textiles into cloth pieces of appropriate size, and then use a Luokou machine to process the cut fabric fragments, forming cotton fibers; then, use conventional textile processing technology to process the obtained cotton fibers into cotton textiles. This method has the advantages of simple operation and low price. After the waste cotton textiles are cut and opened, two products are obtained: one is the fiber that can be continued for textile processing, called spinnable fiber; the other is the fiber that does not have the value of being continued for textile processing, called unavailable spinning fiber. The former can be spun into yarns and then processed into fabrics, the quality of which is no less than that of fabrics woven with nascent fibers; the latter can be made into nonwovens through a certain molding process [16].

Using discarded rags as raw materials, firstly, they are dissociated into fiber forms through a fiber dissociation process; then, dissociated cotton fibers are used as the matrix, isocyanate adhesive PM-50 is used as the adhesive component, and self-designed sizing system, precompression mold, and hot-pressing mold are used to prepare high-performance high-density cotton fiber-based composite materials by hot-pressing processing technology, and through orthogonal experiment method, the effect of processing process parameters on the physics of composite materials is studied. The influence of mechanical properties was studies [17]. Finally, the water resistance modification of composite materials was initially explored.

(1) For the first time, the alkaline hydrogen peroxide mechanical pulping method was used to dissociate waste cotton textiles. By exploring the influence of process conditions on the dissociation process, the better dissociation process parameters were determined, and the fiber analyzer, fiber sieve analyzer, infrared spectrometer, and optical microscope have studied the structure of dissociated cotton fiber under better preparation process conditions [18].

(2) Using dissociated cotton fiber as the matrix and selfmade isocyanate adhesive PM-50 as the adhesive component, high-performance and high-density cotton fiber-based composite materials were successfully constructed through a molding process including sizing, prepressing, and hot-pressing; then explore the process parameters such as adhesive component content, fiber moisture content, hotpressing temperature, hot-pressing time, composite material density, etc., and use the orthogonal analysis method to study the static bending of the composite materials. The influence of physical and mechanical properties such as strength, elastic modulus, internal bonding strength, 24-hour water absorption thickness expansion rate, etc., was studied by adjusting the above process parameters, optimizing process conditions and formula composition, and preparing high-density cotton fiber-based composite materials with excellent performance [19].

(3) In view of the shortcomings of poor water resistance of cotton fiber-based composite materials, referring to the water resistance modification research of other plant fiber composite materials, the method of water resistance modification of cotton fiber-based composite materials was explored, and the method of adding PM-50 adhesive components was used. The content, the heat treatment of the molded composite material, the use of chlorinated paraffin as a waterproofing agent, and the use of reactive silicone waterproofing agent to impregnate the composite material to achieve the water resistance modification of the high-density cotton fiber-based composite material were studied. And its modification effect was studied [20], as shown in Figure 1.

2.3. Monitoring Characteristics. According to the specific structural condition monitoring methods, the currently 


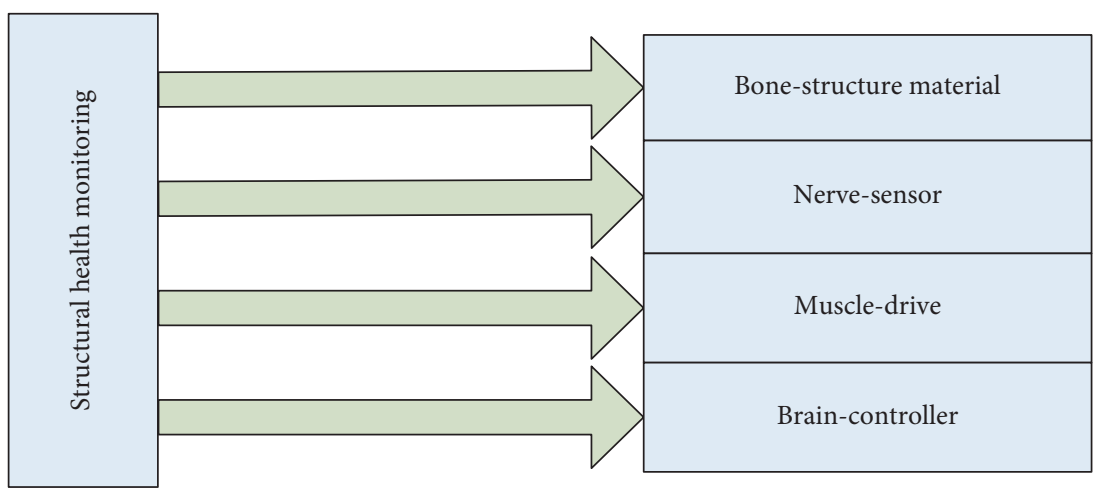

FIGURE 1: Health monitoring structure.

most used monitoring methods are divided into passive monitoring methods and active monitoring methods. The passive structural health monitoring method refers to the monitoring of the structure through sensors and the monitoring of the strain field of civil engineering structures [21]. After that, according to the relevant parameters obtained by monitoring, compare the environment of the current structure to perform modeling to obtain the health of the current structure. This method can also be applied to other aspects [22, 23].

Du Yu's structural health monitoring and evaluation will use prior data collection and processing to estimate the current health of the structure, obtain the current problems of the organization and the possibility of improvement, and estimate its remaining life, so that it can serve for a long time. The use of institutional health technology makes all this possible. It understands the problems of the structure and avoids the damage caused by the aging of the structure. It is of great significance to civil engineering [24]. Moreover, this organization can also be applied to other places. The new health monitoring method can significantly change the loss of people in the process, and the improvement of the method enables new solutions to the problems encountered in the process and saves the cost of investment and maintenance costs. Structural health monitoring can also detect subtle damage in the structure, which cannot be done by other monitoring methods. We have constructed a related formula for damage:

$$
\mathrm{RMSD} \%=\sqrt{\frac{\sum_{a=1}^{a=x}\left(R f\left(W\left(\gamma_{a}\right)\right)-R f\left(W_{0}\left(\gamma_{a}\right)\right)\right)^{2}}{\sum_{a=1}^{a=x}\left(R f W_{0}\left(\gamma_{a}\right)\right)^{2}}} .
$$

The greater the damage, the greater the value of RMSD.

The functional verification of structural health monitoring technology in actual engineering structures is an indispensable link for the technology to become practical. At present, the functional verification of the structural health monitoring system mainly focuses on the monitoring part, mainly to verify the effectiveness of the monitoring method and the impact of the engineering application environment on the monitoring system. With the continuous deepening of functional verification research, in addition to the effectiveness of the monitoring method and the impact of environmental parameters, the long-term stability and reliability of the monitoring method, the impact of the monitoring system on the original performance of the structure, and the effectiveness of the remaining life prediction of the structure, the effectiveness of damage control methods needs to be verified step by step [25].

(1) The energy attenuation is large. Concrete is a material cemented by cement, sand, gravel, and other components with different acoustic impedances, which makes the transmission energy attenuation of ultrasonic waves in concrete much larger than that in metal materials. Because of the difference in the size of concrete structures, granular small aggregates, coarse aggregates, and some unhydrated substances, these particles have their own natural frequencies. When ultrasonic waves pass through the concrete medium, resonance will occur, causing the energy of the ultrasound to continue to weaken. In addition, due to the viscous nature of concrete, the sound wave vibration is converted to heat loss, resulting in absorption and attenuation; refraction and reflection on the heterogeneous interface of the component parts cause various scattering phenomena of sound waves, that is, scattering attenuation; due to the diffusion of the ultrasonic beam, the increase of the propagation distance causes the sound intensity and sound pressure of the sound wave to be weakened, resulting in diffusion attenuation. Therefore, in order to increase the propagation distance of sound waves in concrete, the frequency of ultrasonic inspection of concrete is much lower than that of metal materials, because when the wavelength of ultrasonic wave is greater than the particle size or hole size of concrete aggregate, it can bypass the particles or pores and spread to reduce the attenuation of scattered energy [26].

(2) It has directivity. In concrete ultrasonic testing, because the selected ultrasonic frequency is low, the wavelength is longer, and the diffusion angle is large, the ultrasonic wave emitted by the transmitting sensor is actually a spherical wave with the sensor as the center of the sphere when it propagates in the concrete, and the sound field is directed. The 
performance is very small, and the ultrasonic field occupies all the concrete test block space. The difference in the acoustic impedance of the different constituent materials in the concrete causes the ultrasonic waves to be refracted and reflected disorderly, so that the incident beam is diffused around; in addition, the reflection and refracted waves of the ultrasonic waves in the concrete interfere with each other and superimpose, so that the ultrasonic waves are diffused [27].

(3) The propagation path is complicated. Concrete is a heterogeneous multiphase material. Ultrasonic waves produce reflection and refraction phenomena, so that there are many sound wave propagation paths during the test [28].

(4) The received signal is complicated. Ultrasonic testing of concrete mainly uses longitudinal waves emitted by ultrasonic sensors. When the ultrasonic longitudinal wave propagates in the concrete, the superposition effect of the refraction and reflected longitudinal wave and the transverse wave generated by the waveform conversion effect makes the ultrasonic signal received by the receiving sensor very complicated; the quality and structural defects of the concrete are related to the receiving signal. There is a great correlation between the amplitude of the first wave, the dominant frequency, and the changes in the frequency domain spectrogram of the received signal. Therefore, according to the change law of the received ultrasonic signal, a comprehensive judgment can be made on the strength and defects of the concrete [29]. The received signal formula is

$$
P=r \mu \frac{w_{a} f_{a}}{h_{a}}\left(\phi^{b}-\frac{t}{t+t_{x}} d y^{-e}\right) .
$$

2.4. Monitoring Method. The monitoring theory is derived from the nonlinear partial differential equation of Taylor series expansion movement as

$$
\frac{a^{2} R}{a t^{2}}=b_{o}^{2}\left[1+\frac{w^{\prime \prime}}{w^{\prime}} \frac{a u}{a d}+\ldots\right] \frac{a^{2} R}{a d^{2}} .
$$

Among them, with the displacement of $R$ particle relative to time $t, d$ is the distance of propagation. In this study, $d$ is the length of the cube sample $(100 \mathrm{~mm}) ; w^{\prime}$ and $w^{\prime \prime}$ are second- and third-order elastic constants, and b02 is the wave propagation velocity.

Equation (2) is the equation related to the elastic constant of the nonlinear parameter:

$$
\eta_{2}=-\frac{w^{\prime \prime}}{2 w^{\prime}}
$$

The nonlinear motion equation is changed to

$$
\frac{a^{2} R}{a t^{2}}=b_{o}^{2}\left[1-2 \eta_{2} \frac{a u}{a d}+\ldots\right] \frac{a^{2} R}{a d^{2}} .
$$

The solution of the equation is

$$
R=R_{1} \cos (q x-w d)-\frac{1}{4} \eta_{2} q^{2} R_{2} x \sin 2(q x-w d)+\ldots
$$

The relationship between $R 2$ and $R 3$ can be obtained through equations (5) and (6)

$$
\begin{aligned}
& R_{2}=\left(\frac{\eta_{2}}{4}\right) d^{2} R_{1}^{2} x, \\
& R_{3}=\left(\frac{\eta_{2}^{2}}{8}\right) d^{4} R_{1}^{3} x^{2} .
\end{aligned}
$$

When encountering obstacles, due to the effects of scattering, refraction, and reflection, the amplitude of the basic signal will be attenuated or lost, taking into account the attenuation of the basic signal and the generation of resonance waves. $A 1, A 2$, and $A 3$ represent the sensor receiving signal

$$
\begin{aligned}
& \frac{A 2}{A_{1}^{2}}=\left(\frac{\eta_{2}}{4}\right) d^{2} x, \\
& \frac{A_{3}}{A_{1}^{3}}=\left(\frac{\eta_{3}}{6}\right) d^{3} x .
\end{aligned}
$$

\section{Experiment of Smart Wall Insulation Materials}

\subsection{Preparation Method}

(1) First, it is necessary to evaluate the reusability of waste cotton textiles and select waste cotton textiles with certain reprocessing value. Waste cotton textiles without recycling value need to be processed by other methods. Some waste cotton textiles that have been polluted by harmful substances must be buried or incinerated directly to avoid harm to humans.

(2) Subdivide waste cotton textiles with recycling value into soft waste and hard waste. The former mainly refers to some oil produced during the processing of cotton fiber. These soft wastes still have the characteristics of cotton fiber and can be directly used for spinning into yarn after simple treatment; the latter refers to the cotton fibers processed into fabrics that cannot be used directly like the former. They need to be processed by cutting, opening, and other processes to obtain fiber-shaped products before they can be reused.

(3) For blended fabrics, according to their specific uses, different fiber component separation methods can be used to separate them and then separate them for collection and utilization.

3.2. Experimental Principle. This experiment researches waste textile smart wall insulation materials and uses the principle of vibration measurement for detection. Vibration 
TABle 1: Distribution of health monitoring materials.

\begin{tabular}{lccccc}
\hline & East area & Western region & Southern region & Northern region & Central region \\
\hline Textiles & 12 & 8 & 9 & 4 & 15 \\
Earth and rock structure & 18 & 13 & 11 & 9 & 17 \\
Concrete structure & 22 & 17 & 19 & 12 & 16 \\
Steel structure & 18 & 11 & 12 & 11 & 21 \\
\hline
\end{tabular}

is a complex physical process. In the field of mechanical engineering, the reciprocating motion of objects changing with time is common, and mechanical vibration has advantages and disadvantages. When the structure is excited and its frequency is the same as its natural frequency, it will resonate and cause interference and harm to the environment. Therefore, for most machinery and engineering structures, it is generally required to reduce the magnitude of the possible vibrations. Control within a certain range. Especially in the use of high-speed machinery and equipment, people are sometimes required to use the vibration signal generated by the system for condition monitoring and fault prediction and can timely and automatically take a variety of more effective measures to remove or prevent the system. Excessive or even more dangerous vibration conditions may occur at any time, so as to ensure the safety and reliability of machinery equipment and engineering facilities.

$$
\begin{aligned}
d m & =\frac{g_{m}(\Phi / \Omega)^{2}}{\sqrt{\left[1-(\Phi / \Omega)^{2}+(2 \phi \Phi / \Omega)^{2}\right]}}, \\
a & =\arctan \frac{2 \phi(\Phi / \Omega)}{1-(\Phi / \Omega)^{2}} .
\end{aligned}
$$

Among them, $d m$ represents the amplitude of the vibrating structure shell, $g m$ is the vibrating body, and a represents the relationship of the signal $x / y$.

3.3. Experimental Purpose. This article is based on the theoretical results of industrial economics and sports industry economics, draws on the domestic and foreign sports industry structure theoretical research results, and uses literature, comparative research, mathematical statistics, logical analysis, and other methods to make smart walls from waste textiles. And for its application in civil engineering to conduct in-depth analysis, study its application and characteristics in health inspection.

\section{Civil Engineering Health Monitoring Experiment Analysis}

4.1. Smart Wall Materials. In civil engineering health monitoring, there are various materials for health monitoring, such as soil, concrete, steel, and textiles. We have made statistics on related materials. The specific data are shown in Table 1 and Figures 2 and 3.
From the statistical results, we can clearly see that, in the civil engineering health check, the materials currently used in different places are different. The most used are earth and stone and concrete structures, while the textiles are less used. This aspect is due to different local conditions, such as engineering soil and environment, etc. On the other hand, due to the small scale and influence of smart walls made by textiles, fewer people use them.

4.2. Different Materials Receive Signal Value and Amplitude Value. For different materials, we input the parameters into the relevant calculation formulas, and obtain the values of the relevant parameters through the computer. The specific data are shown in Table 2 and Figures 4 and 5.

From the chart, we can see that, among these materials, the smart wall made of preventive materials has the strongest signal receiving ability, reaching 0.752 with an amplitude of 1.95 , ranking second. This shows that, in theory, the effect of smart walls made of textiles will be better than those made of other materials.

4.3. The Role of Different Materials in Health Monitoring. In health monitoring, the main tests are its sensing, driving, and controlling functions. We have also made relevant statistics on these functions of different materials. The specific data are shown in Table 3 and Figures 6 and 7.

From the chart, we can clearly see that, in the experiment, the smart wall made of textiles is far superior to other materials in sensing and control, and its driving function is only slightly lower than that of other materials. It can replace other materials and take on the function of health monitoring.

\subsection{Damage Rate of Different Materials in Monitoring.} Civil engineering health inspections not only need to be able to monitor the relevant data, but also have very strict requirements for the monitoring materials themselves. Through experiments, we conducted 100 experiments on different materials in the monitoring to determine the degree of damage. Related statistics and specific data are shown in Table 4 and Figures 8 and 9.

From the above chart, we can see that, in the antidamage experiment, the smart wall made of textile performed well, with the largest number of undamaged and lightly damaged, and the least of severely damaged. Other materials have a higher proportion of severe damage than textiles. This shows that textiles can replace other materials in smart wall materials. 


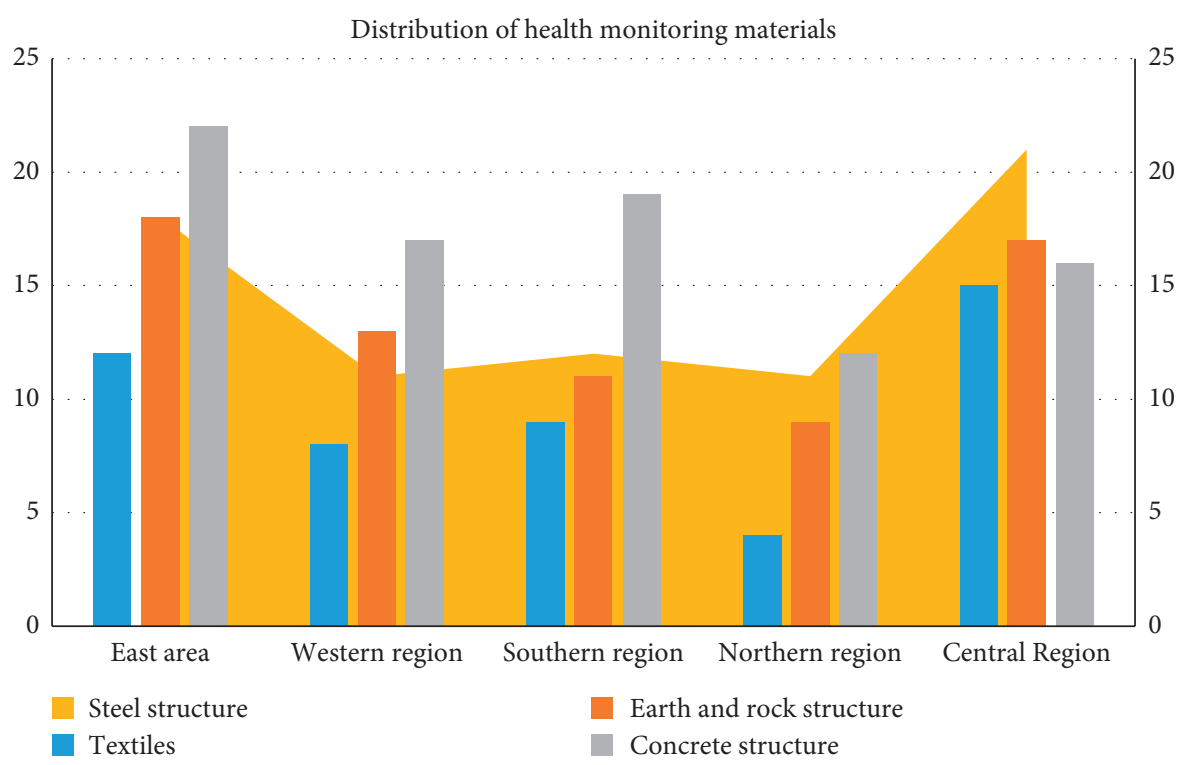

FIGURE 2: Distribution of health monitoring materials.

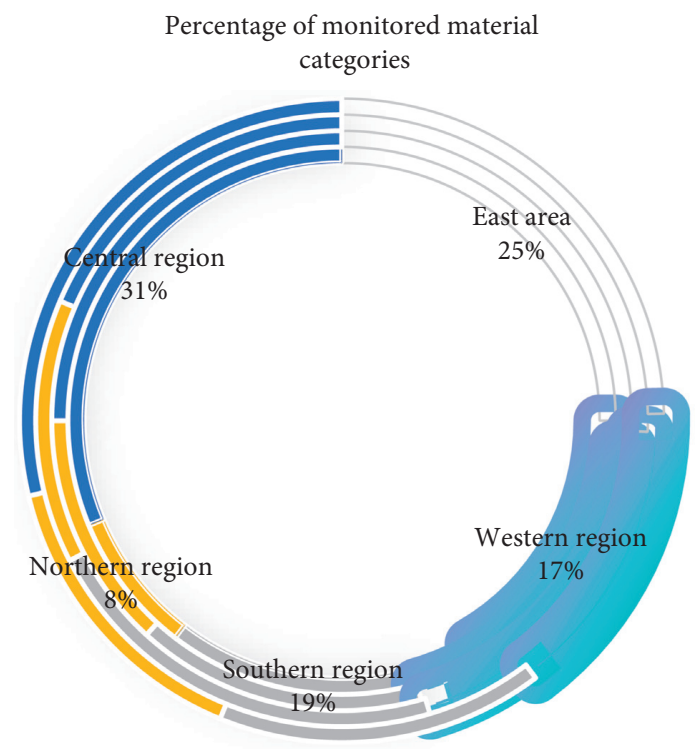

FIGURE 3: Percentage of monitored material categories.

TABLE 2: Material parameter value.

\begin{tabular}{lcc}
\hline & Receive signal & Amplitude \\
\hline Textiles & 0.752 & 1.95 \\
Earth and rock structure & 0.615 & 2.01 \\
Concrete structure & 0.672 & 2.42 \\
Steel structure & 0.592 & 1.79 \\
\hline
\end{tabular}

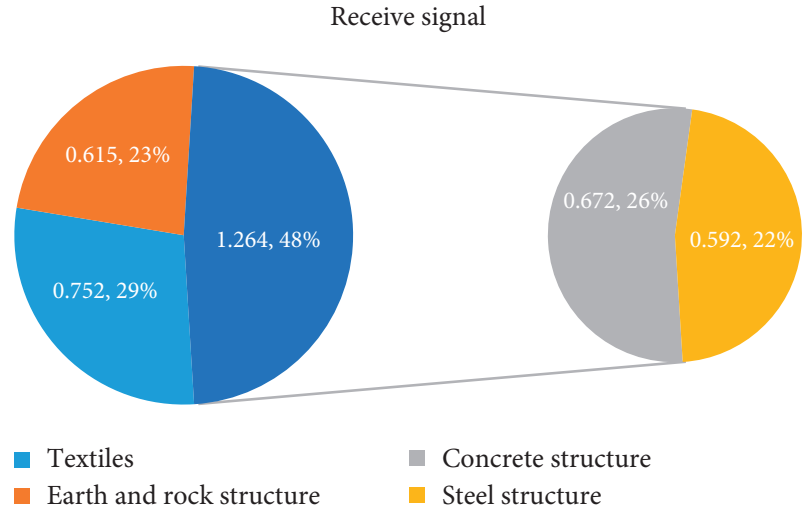

Figure 4: Parameter values of different materials. Influence of materials on parameters

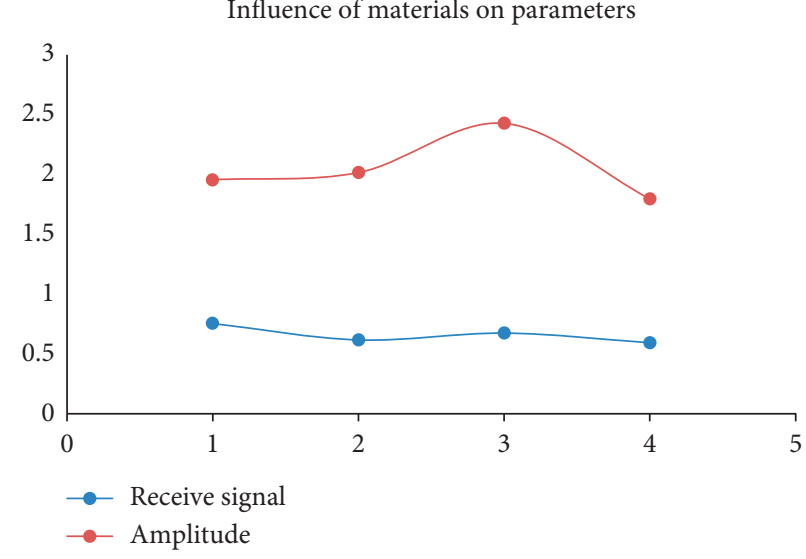

Figure 5: Influence of materials on parameters. 
TABLE 3: The role of different materials.

\begin{tabular}{lccc}
\hline & Sensing effect & Driving effect & Control effect \\
\hline Textiles & 1.257 & 1.023 & 1.758 \\
Earth and rock structure & 1.045 & 1.231 & 1.542 \\
Concrete structure & 0.951 & 1.010 & 1.348 \\
Steel structure & 0.941 & 1.021 & 1.537 \\
\hline
\end{tabular}

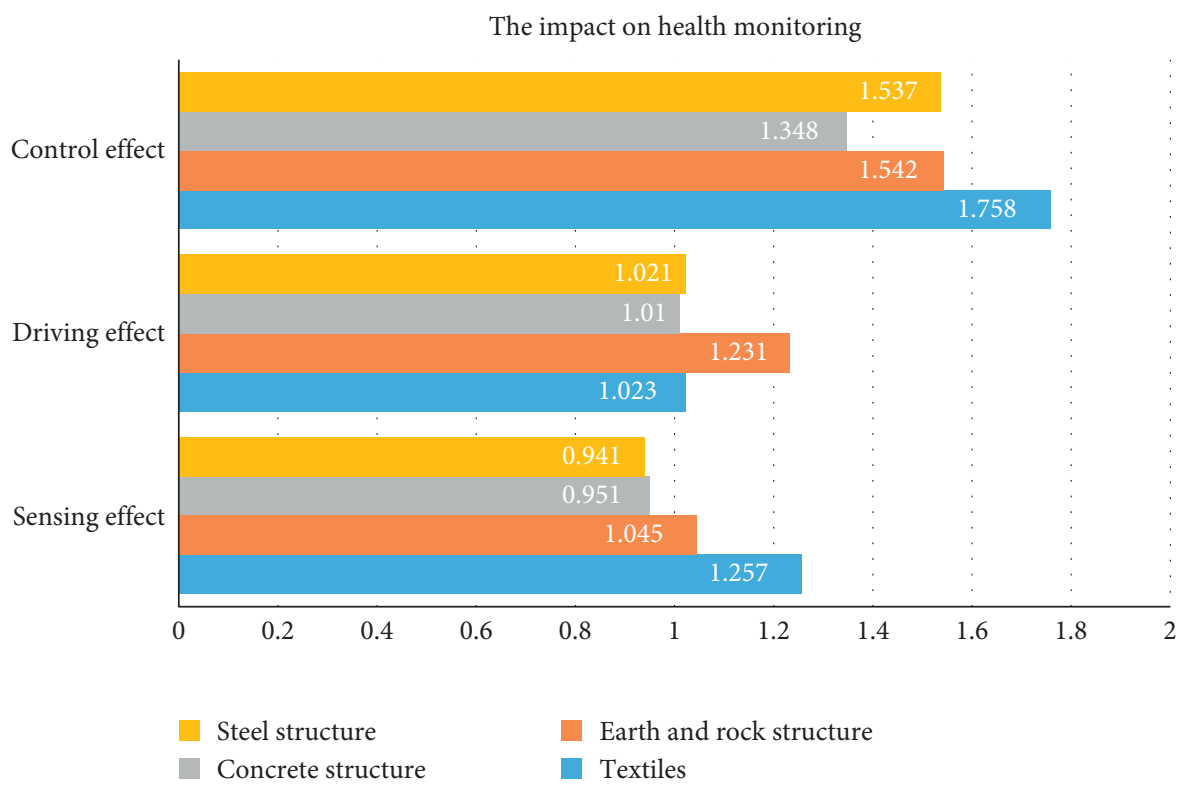

FIgURE 6: The impact of materials on health monitoring.

The impact of different materials on health monitoring

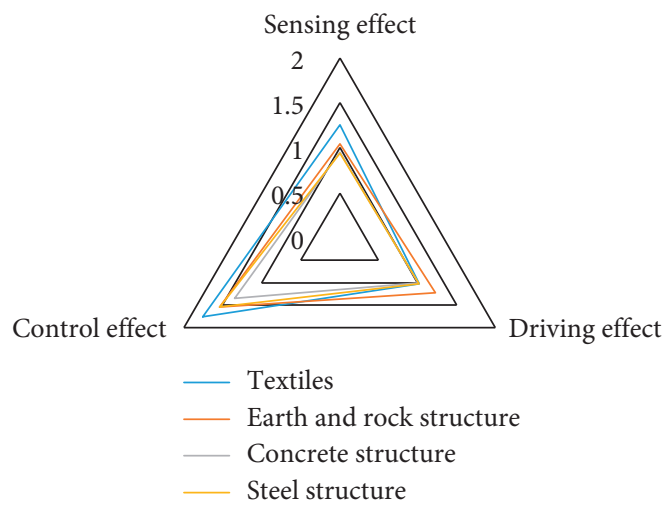

FIGURE 7: The impact of different materials on health monitoring.

TABle 4: Antidamage test.

\begin{tabular}{lcccc}
\hline & No damage & Minor damage & Moderate damage & Damaged severely \\
\hline Textiles & 53 & 32 & 10 & 5 \\
Earth and rock structure & 32 & 46 & 16 & 6 \\
Concrete structure & 36 & 42 & 17 & 5 \\
Steel structure & 33 & 47 & 9 & 11 \\
\hline
\end{tabular}




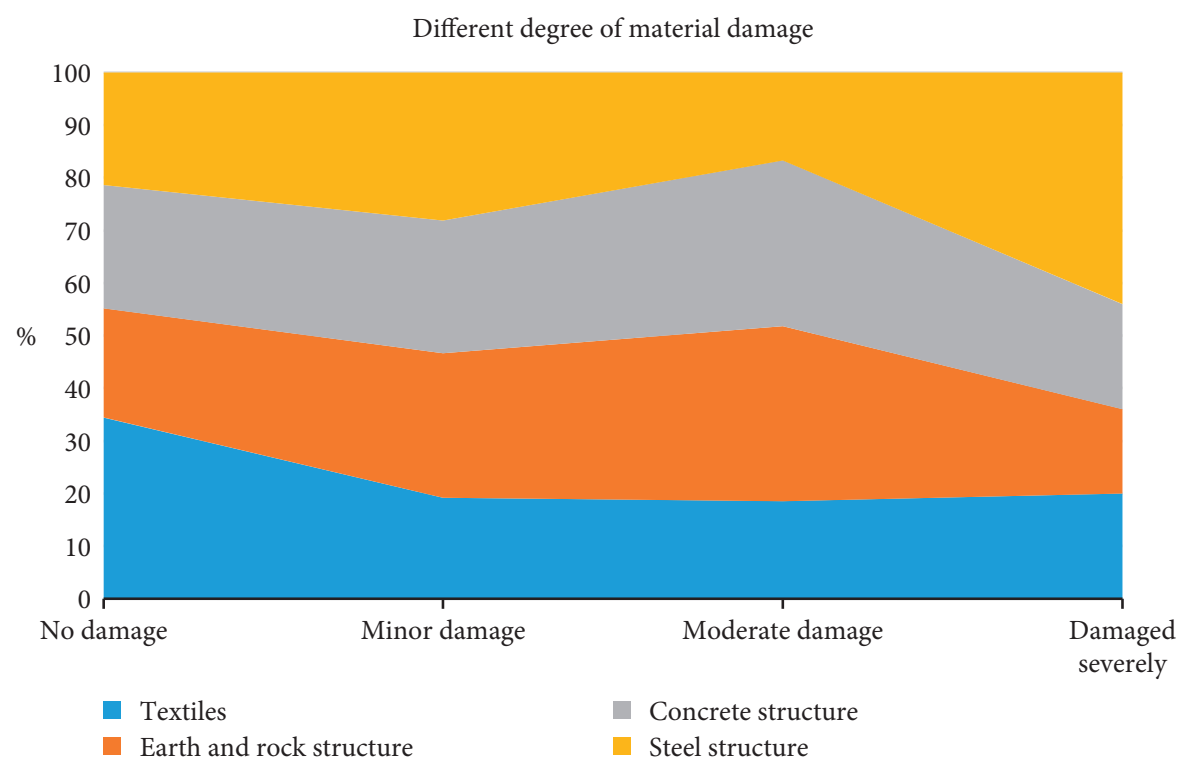

FIgURE 8: Different degree of material damage.

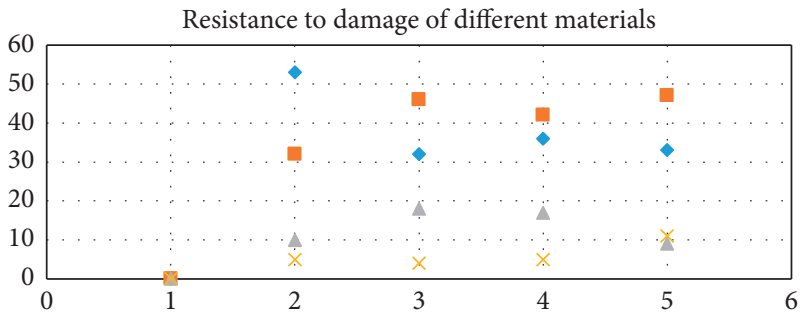

Figure 9: Resistance to damage of different materials.

\section{Conclusions}

Our country has not yet established a relatively complete recycling and treatment mechanism for waste cotton textiles. Waste cotton textiles are basically regarded as domestic garbage and discarded directly. The current situation of recycling and reuse is worrying, which has attracted the attention of relevant government departments. The current recycling methods of waste cotton textiles have various drawbacks, and the current production technology of the textile industry has strict requirements on the length of the recycled cotton fiber, and only a small part of it has better texture. Waste cotton textiles can be fully recycled. More waste cotton textiles or blended textiles of average quality are difficult to recycle. Therefore, it is of great significance to develop a new way to recycle waste cotton textiles with universality and economy.

This paper analyzes the investment cost and energy consumption of waste textiles to make thermal insulation materials in the whole life cycle stage and studies the minimum total investment cost, economic thickness, and investment recovery of the three types of base walls in the hot summer and cold winter areas of the full-life cycle insulation materials. Energy-saving characteristic parameters such as period and economic benefits have concluded that thermal insulation materials made of waste textiles are more suitable for health monitoring than other materials, which can effectively reduce safety risks and reduce the probability of accidents.

The research of health monitoring technology is a Frontier research field composed of many disciplines. The research content involves materials, engineering control, mechanics theory, information processing, etc. Multiple research fields include many modules and how to make them mutual layout coordination, a choice to determine real-time (continuous) and discontinuous structural health monitoring systems. It is believed that, with the deepening of research, the use of waste textiles to make smart wall insulation materials for health monitoring will become more and more popular.

\section{Data Availability}

The data underlying the results presented in the study are available within the manuscript.

\section{Conflicts of Interest}

The author declares have no conflicts of interest.

\section{Acknowledgments}

This work was supported by major natural science research projects of colleges and universities of Anhui Provincial Department of Education (KJ2017ZD39).

\section{References}

[1] W. Liu, "Review of safety assessment, health monitoring and diagnosis of civil engineering structures," Civil Engineering Technology and Design, vol. 1, no. 17, pp. 134-136, 2016.

[2] Y. Han, "General civil engineering structural health monitoring system platform," Electronic Technology and Software Engineering, vol. 1, no. 21, pp. 152-153, 2017. 
[3] Li Hui, Y. Bao, S. Li et al., "Data science and engineering of structural health monitoring," Engineering Mechanics, vol. 32, no. 8, pp. 1-7, 2015.

[4] B. Ding, J. Cui, J. Chen et al., "Structural health monitoring system and its application in engineering," Journal of Xuzhou Institute of Technology: Natural Science Edition, vol. 32, no. 2, pp. 72-76, 2017.

[5] L. Qin, "Briefly on the health monitoring of civil engineering structures," Shanxi Architecture, vol. 41, no. 9, pp. 46-47, 2015.

[6] X. Yang, "Research and application progress of optical fiber health monitoring methods in civil engineering," Metallurgical Management, vol. 393, no. 7, pp. 66-67, 2020.

[7] B. Zhang, "Civil engineering structure safety assessment, health monitoring and diagnosis research," Urban Construction Theory Research (Electronic Edition), vol. 300, no. 18, pp. 36-37, 2019.

[8] R. Li, "Research and development status of intelligent sensing materials, sensors and health monitoring systems for civil engineering structures," Architecture Engineering Technology and Design, vol. 1, no. 2, pp. 72-76, 2016.

[9] Engineering Mechanics Branch of Chinese Academy of Sciences Association of Senior Scientists, "Research on health monitoring technology of fatigue crack growth," Engineering Mechanics Branch of Association of Senior Scientists of Chinese Academy of Sciences, vol. 3, no. 23, pp. 172-174, 2016.

[10] J. He, "Research status and progress of civil engineering structure health monitoring system," Doors and Windows, vol. 1, no. 11, p. 186, 2017.

[11] Z. Meng, "Research status and progress of civil engineering structure health monitoring system," Architectural Engineering Technology and Design, vol. 1, no. 17, pp. 32-38, 2016.

[12] X. Wang and P. Xu, "Research on civil engineering structure health monitoring and application analysis of monitoring system," Jiangxi Building Materials, vol. 1, no. 2, pp. 132-134, 2017.

[13] L. Cui, "Application of structural health monitoring technology in civil engineering," Sichuan Building Materials, vol. 1, no. 2, pp. 44-45, 2015

[14] Y. Wang, "Discussion on health monitoring and early warning of civil engineering structures," Building Supervision, Inspection and Cost, vol. 1, no. 5, pp. 28-31, 2016.

[15] H. Liu, "A review of safety assessment, health monitoring and diagnosis of civil engineering structures," Encyclopedia Forum Electronic Journal, vol. 1, no. 9, pp. 294-296, 2018.

[16] K. You, "Research status and progress of civil engineering structural health monitoring system," Friends of Humanities, vol. 1, no. 1, pp. 242-243, 2018.

[17] H. Li, "Review of safety assessment, health monitoring and diagnosis of civil engineering structures," Civil Engineering Technology and Design, vol. 1, no. 25, pp. 2164-2166, 2018.

[18] H. Cai, "Research on the application of structural health monitoring technology in civil engineering," Civil Engineering Technology and Design, vol. 1, no. 15, pp. 312-314, 2018.

[19] F. Mei, "Analysis on the research status of civil engineering structure health monitoring system," Architecture Engineering Technology and Design, vol. 1, no. 24, pp. 4215-4216, 2017.

[20] L. Long, "Analysis of structural health monitoring of civil engineering in my country," Engineering Technology(Full Text Edition), vol. 1, no. 10, pp. 225-227, 2016.

[21] L. Zhao, "Research on the health monitoring methods of civil engineering structures," Architectural Engineering Technology and Design, vol. 1, no. 14, pp. 2510-2512, 2017.
[22] C. Lei, "Research status and progress of civil engineering structural health monitoring system," Civil Engineering Technology and Design, vol. 1, no. 35, pp. 1734-1736, 2016.

[23] X. Zhang, "A review of structural safety assessment, health monitoring and diagnosis of civil engineering," Ju She, vol. 1, no. 29, pp. 9-11, 2017.

[24] Y. Liu, "Analysis of the research status and progress of civil engineering structural health monitoring systems," Speed Reading (Middle), vol. 1, no. 6, pp. 50-53, 2016.

[25] L. Kun, "Analysis of research status and progress of civil engineering structural health monitoring system," Chinese Science and Technology Journal Database (Full Text Edition) Engineering Technology, vol. 1, no. 8, pp. 123-125, 2016.

[26] B. Zhang, J. Changzhi, G. Wang et al., "Application progress of optical fiber health monitoring methods in civil engineering," Fire Department: Electronic Edition, vol. 1, no. 4, pp. 88-89, 2016.

[27] L. Jiang, "Civil engineering intelligent health monitoring and diagnosis system," Urban Construction Theoretical Research (Electronic Edition), vol. 5, no. 34, pp. 834-835, 2015.

[28] Y. Zhou, "Research status of civil engineering structure health monitoring system," Architectural Engineering Technology and Design, vol. 1, no. 29, pp. 677-678, 2016.

[29] $\mathrm{S}$. Wu, "The status quo and development of civil engineering structural health monitoring," Heilongjiang Science and Technology Information, vol. 1, no. 23, pp. 218-219, 2015. 